\title{
COST-EFFECTIVENESS ANALYSIS OF CPOE IN HOSPITAL SETTING: A SYSTEMATIC REVIEW
}

\author{
Dian Ekawati'), Ede Surya Darmawan²) \\ 1)Department of Hospital Administration, Faculty of Public Health, Universitas Indonesia \\ ${ }^{2)}$ Department of Health Policy and Administration, Faculty of Public Health, \\ Universitas Indonesia
}

\begin{abstract}
Background: Medication administration process is subject to error. In many cases it can lead to adverse drugs events (ADEs). An implication of ADEs is increased cost due to extended length of stay. Based on several studies, the use of computerized physicians order entry (CPOE) system can reduce the incident of $\mathrm{ADEs}$ in hospital which can indirectly reduce the ADEs related cost. A way to examine the efficiency of cost is to observe the number of cost incurred due to the effects of error that occur. This study aimed to systematically review articles related to the cost-effectiveness analysis of CPOE in hospital setting.

Subjects and Method: This was a systematic review study using online databases, such as PubMed, Embase, and other sources. The main theme of this study was costs related CPOE implementation. The inclusion criteria were studies cost savings from the effects of ADEs and cost effectiveness related to the use of a computerized system on the CPOE. The exclusion criteria were studies with descriptive analysis and studies without reporting on CPOE and cost effectiveness. This data were collected and analyzed with PRISMA flow diagram.

Results: A total of 11 studies met the inclusion criteria. Ten studies obtained cost efficiency due to the use of computerized system. The decrease in cost were incurred as a result of the decrease in the incidence of EDAs converted into annual cost. Comparison of cost reduction was done by comparing cost incurred when using a CPOE system with a paper-based system. However, there was a study conveyed ineffectiveness in small size hospital and located at rural area, because the cost was higher than the revenue obtained.
\end{abstract}

Conclusions: CPOE is proven to be cost-effective in lowering the hospital costs incurred owing to the ADEs.

Keywords: cost-effectiveness, cost analysis, CPOE, ADEs, medication administration process, hospital.

\section{Correspondence:}

Dian Ekawati. Department of Hospital Administration, Faculty of Public Health, Universitas Indonesia, Depok, West Java, Indonesia. Email: dianeka1981@gmail.com. Mobile: +628567650569.

\section{BACKGROUND}

Computerized Physician Order Entry (CPOE) refers to the process of a medical professional entering and sending medication orders and treatment instructions electronically via a computer application instead of on paper charts. Medication administration process is subject to error. In many cases it can lead to Adverse Drugs Events (ADEs) (Scott, 2016).

Most adverse drug events are caused by errors in prescription. this error causes costs to arise as a result of errors (Scott, 2016). By using CPOE, it is expected to reduce the cost of services at the hospital. In addition, it also improves the quality in patient service quality (Weiss et al., 2010).

This study aims to assess the articles on the costs of computerized in the hospital health system of CPOE on the magnitude of the effect in cost effectiveness, which can be used as a computerized health system in the hospital that compare with manual prescription (Raj Gopalan, 2017). 


\section{SUBJECTS AND METHOD}

This study conducted in form of narrative review by implementing literature search strategies suitable to topic of writing. All articles were assessed for information about cost effectiveness that correlation with reduce the ADEs cause of using CPOE systems.
The study was done in April 2019 facilitated by electronic library provided, which goes through the PubMed, Embase and other online literature publication library. The keyword uses in the search were "CPOE" and "ADEs" to focus the search on the information that related cost effectiveness (Table 1).

Table 1. Inclusion and Exclusion Criteria

\begin{tabular}{ll}
\hline \multicolumn{1}{c}{ INDICATOR } & \multicolumn{1}{c}{ DESCRIPTION } \\
\hline Participant (P) & $\begin{array}{l}\text { Patients admitted to hospital through emergency department or inpatient. No } \\
\text { limit on patient diagnosis. }\end{array}$ \\
$\begin{array}{l}\text { Intervention (I) } \\
\text { Comparison (C) }\end{array}$ & $\begin{array}{l}\text { Computerized Physician Order Entry (CPOE) } \\
\text { paper prescribing, manual prescribing } \\
\text { Outcome (O) }\end{array}$ \\
$\begin{array}{ll}\text { Cost-effectiveness of CPOE system on the selected participants and region } \\
\text { Study Design }\end{array}$ & $\begin{array}{l}\text { We include all type of study design but limited to scholarly journal, dissertation } \\
\text { and thesis publications. Study without comparison groups were also excluded. }\end{array}$ \\
\hline
\end{tabular}

There were 64 articles with the keyword CPOE and ADEs correlated with cost effecttiveness. There were 67 duplicates and 21 articles excluded based on title and abstract.
Full-text articles were assessed for eligibility and after the inclusion and exclusion selection. A total of eight studies met the criteria for further analysis (Figure 1).

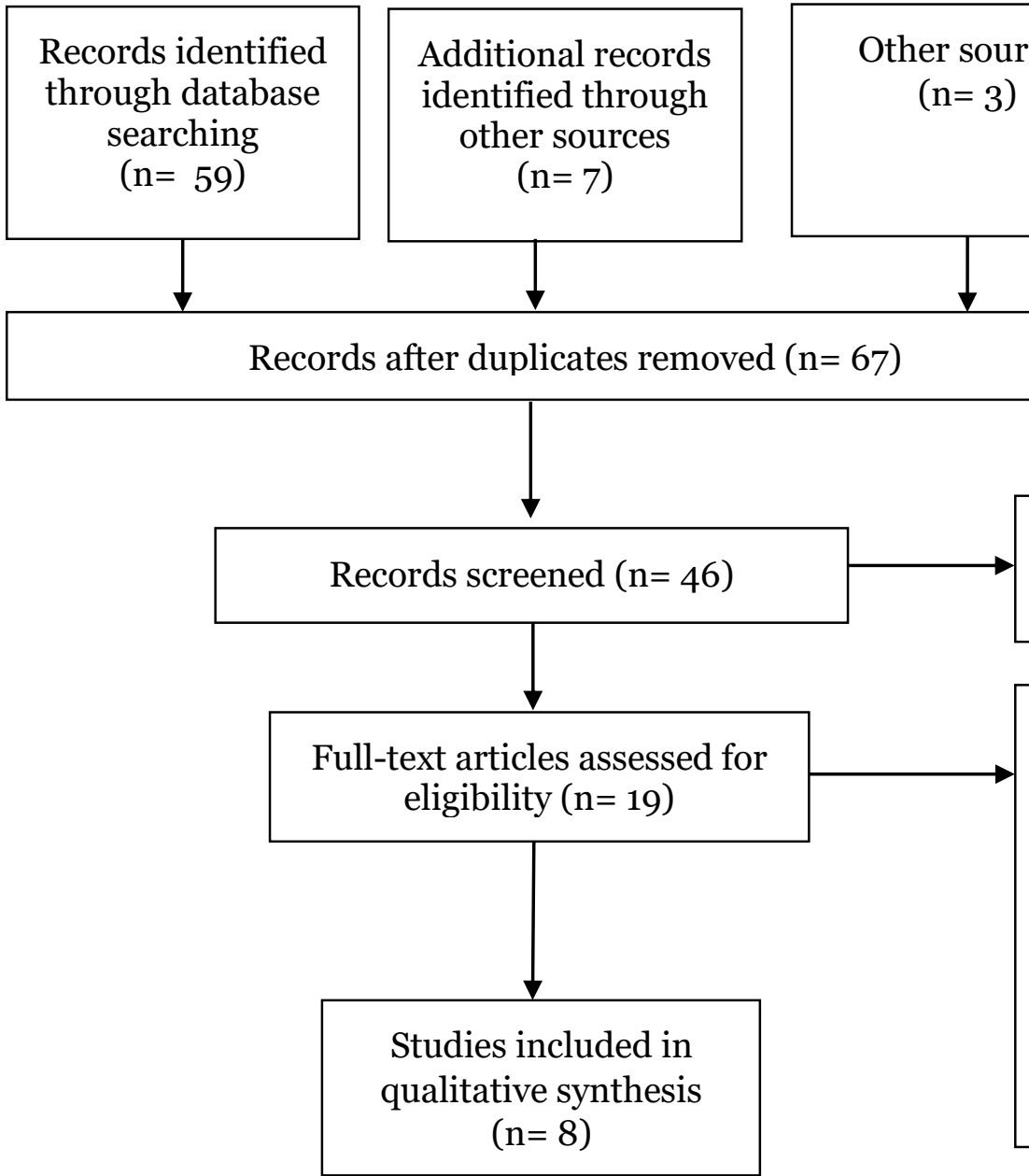

Records excluded $(n=21)$

Figure 1. PRISMA flow diagram 


\section{RESULTS}

Base on this review, Cost Effectiveness of CPOE can be analyzed based on the following criteria, showed in Figure 2. In the 8 studies, the results of the decrease in costs were incurred as a result of the decrease in the incidence of EDAs converted into annual costs.

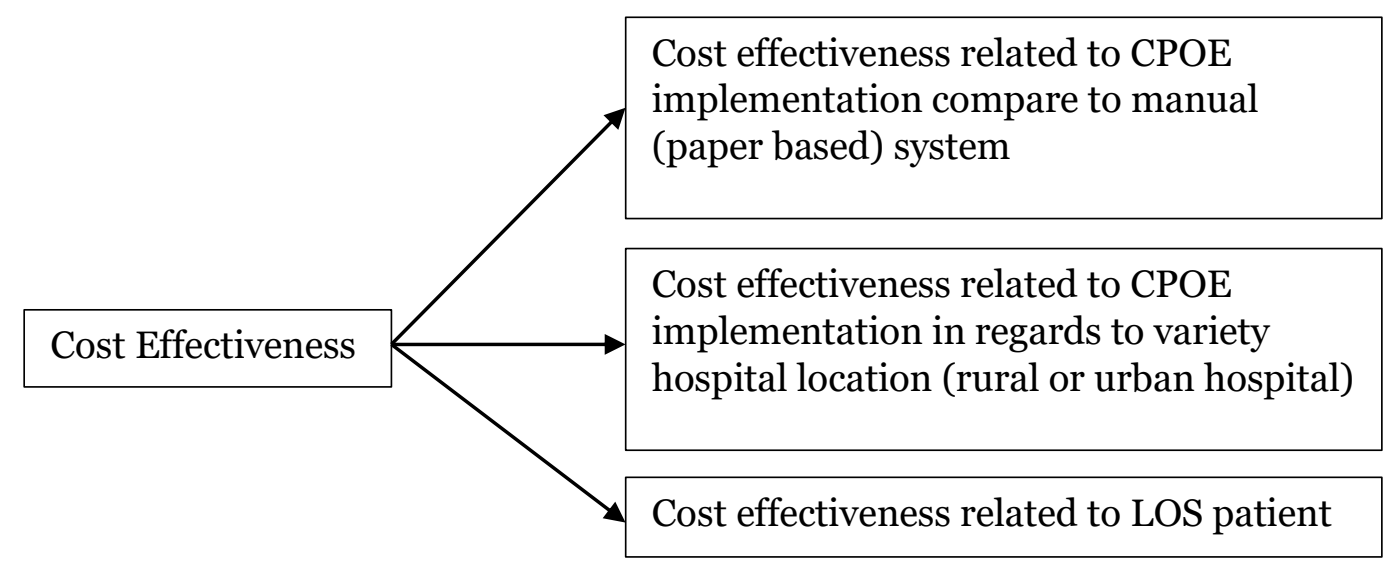

Figure 2. The Analysis of Cost Effectiveness of CPOE

Comparison of cost reduction is done by comparing costs incurred when using a CPOE system with a paper-based system. However, there were 3 studies conveyed ineffectiveness CPOE. It happened in small size hospital and located at rural area, because the cost was higher than the revenue obtained. Besides that there was study that also show that there is no significant relationship between the use of CPOE and a decrease in costs due to shorter LOS.

Table 2. Articles reviewed in this study

\begin{tabular}{|c|c|c|}
\hline No. & Review & Cost effectiveness \\
\hline 1. & $\begin{array}{l}\text { "Cost-effectiveness analysis of a hos- } \\
\text { pital electronic medication manage- } \\
\text { ment system" }\end{array}$ & $\begin{array}{l}\text { save cost around } \$ 63-66 \text { per admission } \\
(\$ 97740-\$ 102000 \text { annually })\end{array}$ \\
\hline 2. & $\begin{array}{l}\text { "Implementation of Hospital } \\
\text { Computerized Physician Order Entry } \\
\text { Systems in a Rural State: Feasibility } \\
\text { and Financial Impact" }\end{array}$ & $\begin{array}{l}\text { The reference case model assumes no im- } \\
\text { pact of CPOE on revenues (except Medi- } \\
\text { care for critical access hospitals) and no im- } \\
\text { pact on other costs. Using CPOE cost estima- } \\
\text { tes, critical access hospitals would have to } \\
\text { trim annual operating costs by about } 3.1 \% \text { to } \\
\text { offset the costs of CPOE over } 10 \text { years. For } \\
\text { rural hospitals, the required cost offset is } \\
\text { about } 4.5 \% \text { of costs. The required offset is } \\
\text { about } 1.1 \% \text { per year for rural-referral hos- } \\
\text { pitals and } 1.0 \% \text { per year for urban hospitals. }\end{array}$ \\
\hline 3 . & $\begin{array}{l}\text { "Cost-Effectiveness of a Computerized } \\
\text { Provider Order Entry System in Im- } \\
\text { proving Medication Safety Ambulatory } \\
\text { Care" }\end{array}$ & $\begin{array}{l}\text { In the base case, CPOE dominated paper } \\
\text { prescribing, that is, CPOE cost } \$ 18 \text { million } \\
\text { less than paper prescribing, and was } \\
\text { associated with } 1.5 \text { million and } 14,500 \text { fewer } \\
\text { medication errors and ADEs, respectively, } \\
\text { over } 5 \text { years. In the scenario that reflected a } \\
\text { practice group of five providers, CPOE cost }\end{array}$ \\
\hline
\end{tabular}


4. "Cost-effectiveness of an electronic medication ordering system (CPOE/CDSS) in hospitalized patients."

5. "Modelling the expected net benefits of interventions to reduce the burden of medication errors. “

6. "Cost-Effectiveness Analysis of an Automated Medication System Implemented in a Danish Hospital Setting”

7. "Is Computerized Physician Order Entry Use Associated with a Decrease in Hospital Resource Utilization in Hospitals That Care for Children?"

8. "A computer-assisted Management Program for antibiotics and antiinfective agents."
\$265,000 less than paper prescribing, was associated with 3875 and 39 fewer medication errors and ADEs, respectively, over 5 years

Cost per patient/day for CPOE is slightly higher compare to paper-based system. (€14.91 compare to $€ 12.37$ ).

Estimated monetary valuations of the health effects of pADEs has net benefit $£ 31$. $£ 27.25$ and $£ 13.1$ million for CPOE, ward pharmacist and bar coding.

Cost effectiveness ratio around $€ 2.01$ per avoided administration error, $€ 2.91$ per avoided procedural error and $€ 19.38$ per avoided clinical error.

CPOE use was associated with a 0.3 day increase in hospital length of stay and an increase in hospital charge of $\$ 1770$. And there was no difference in length of stay and a nonsignificant higher cost of $\$ 70$ per case in total charge

Reductions in the cost of anti-infective agents ( $\$ 102$ vs. $\$ 340$ and $\$ 427$ ), and the total cost of hospitalization $(\$ 26,315$ vs. $\$ 35,283$ and $\$ 44,865)$.

order entry and bar coding, have the potential to improve medication safety (Sultana et al., 2013).

In this reviews we can explain how many cost that can reduce by CPOE system. All reviews show that CPOE can reduce cost of medication error compare with paper-based system. There are variety of cost reduction in every study. However, there were 3 studies conveyed ineffectiveness of CPOE, because to implement CPOE is a daunting task due to there are significant barriers impeding adoption, in particular the high capital costs involved and the fact that adoption requires major/disruptive changes in the workflow of a hospital. Nevertheless, based on these reviews, the use of CPOE is effective in reducing costs caused by ADEs in hospital.

CPOE is recommended to be used in order to reduce cost that causes of ADE's in hospital setting. Despite there will be incremental cost for CPOE implementation, it is 
not significant compare to cost effectiveness due to improved patient safety and efficiently.

\section{REFERENCE}

Hug BL, Keohane C, Seger DL, Yoon C, Bates DW (2012). The costs of adverse drug events in community hospitals. Joint Commission Journal on Quality and Patient Safety, 38(3): 120-126. https://doi.org/10.1016/S15537250(12)38016-1

Raj Gopalan M (2017). The High Cost Of Medication Errors. Retrieved from https://www.healthitoutcomes.com/doc/the-high-cost-of-medicationerrors-0001
Scott L (2016). Medication errors. Nursing Standard (Royal College of Nursing (Great Britain), 30(35): 61-62. https://doi.org/10.7748/ns.30.35.61.s49

Sultana J, Cutroneo P, Trifirò G (2013). Clinical and economic burden of adverse drug reactions. Journal of Pharmacology and Pharmacotherapeutics, 4. https://doi.org/10.4103/o976-500X.120957

Weiss AJ, Freeman WJ, Heslin KC, Barrett ML (2010). Adverse Drug Events in U.S. Hospitals, 2010 Versus 2014. Retrieved from www.ahrq.gov/sites/default/files/publications/files/interimhacrate2014_2.pdf. 